\title{
PREDICTIVE FACTORS OF HEMORRHAGIC ISCHEMIC STROKE DETECTED BY CT AND MRI GRADIENT-ECHO T2 WEIGHTED IMAGE (GRE)
}

By

\author{
Hamed G.H. Ibrahim ${ }^{1}$, Tarek I. Menicie ${ }^{1}$, Khaled I.El- Noueam ${ }^{2}$, \\ Mohamed A. Ahmed ${ }^{3}$, Ahmad Farag Ibrahim ${ }^{1}$ \\ ${ }^{1}$ Neurology Dep., Faculty of medicine, Al-Azhar University \\ ${ }^{2}$ Diagnostic Radiology Dep., Faculty of medicine, Alexandria University \\ ${ }^{3}$ Clinical Pathology Dept., Medical Armed Forces Academy \\ E-mail: afathyneuro@gmail.com
}

\begin{abstract}
Background: Risk of hemorrhage is significantly increased in large infarcts, with mass effect supporting the importance of edema for tissue damage and the deleterious effect of late reperfusion when edema resolves. In some instances, the rupture of the vascular wall secondary to ischemia-induced endothelial necrosis might cause an intra-infarct hematoma. Vascular rupture can explain very early hemorrhagic infarcts and early intra infarct hematoma (between 6 and 18 hours after stroke), whereas hemorrhagic transformation usually develops within 48 hours to 2 weeks. Intra cerebral hemorrhage (ICH) occurs as a result of bleeding from an arterial source directly into the brain parenchyma and accounts for 5-15\% of all strokes.

Objective: The aim of this study was to determine the predictive factors of hemorrhagic transformation in patient with acute ischemic stroke detected by brain CT and MRI gradient echo T2 weighted image (GRE).

Patients and Methods: This was a cross sectional randomized prospective study carried out on 60 patients (32 males and 28 females), admitted at Neurology Department and Stroke Unit of Mostafa Kamel Military Hospital, within the first 24 hours of their symptoms. The study was carried out during the period from 1st of January 2018 till the end of December 2018.

Results: The results of this study showed that the size of infarction was small in $27(45.0 \%)$ patients and large in $33(55.0 \%)$ patients, the micro bleeds were found in $32(53.3 \%)$ of the studied patients, and the hemorrhagic transformation was found in $11(18.3 \%)$ of the patients. The results showed that there was a significant relation between micro bleeds and hypertension, diabetes mellitus, dyslipidemia, past history of stroke, cardiac disease and hemorrhagic transformation. The small size infarction showed a higher percent of micro bleeds. Regarding the hemorrhagic transformation, the risk factors were the size of infarction, anticoagulant use, hypertension, diabetic and cardiac diseases.
\end{abstract}

Conclusion: The most predictive factors of hemorrhagic transformation was the size of infarction (higher in large), micro bleed, anticoagulant use, hypertension, dyslipidemia and cardiac disease, while the most predictive factors of micro bleeds were the size of infarction (higher in small), age, hypertension, dyslipidemia, past history of stroke, diabetes mellitus, and cardiac disease.

\section{INTRODUCTION}

Stroke is defined as either symptoms lasting more than 24 hours or imaging of an acute clinically relevant brain lesion in patient with rapidly vanishing symptoms. Patients with symptoms lasting less than 24 hours but with infarction imaged by MRI have been reclassified as having 


\section{HAMED G.H. IBRAHIM et al.,}

stroke instead of transient ischemic attack (Sacco et al., 2013).

Advances in neuroimaging technology have resulted in a virtual explosion in the amount of pathologic information that can be obtained in the clinical stroke setting. This neuroimaging revolution has led to a much better understanding of cerebrovascular and tissue pathology, creating a wide array of opportunities for acute treatment and secondary prevention (Malhotra and Liebeskind., 2017).

Cerebral hemorrhage is one of the major complications of anti-coagulation and antiplatelet therapies instituted for prevention of ischemic stroke. The anticoagulant- related risk factors for cerebral bleeding were leukoaraiosis and age older than 65 years, in addition to the intensity of anticoagulation (Saji et al., 2016).

Risk of hemorrhage is significantly increased in large infarcts with mass effect supporting the importance of edema for tissue damage and the deleterious effect of late reperfusion when edema resolves. In some instances, the rupture of the vascular wall secondary to ischemia-induced endothelial necrosis might cause an intrainfarct hematoma. Vascular rupture can explain very early hemorrhagic infarcts and early intra infarct hematoma (between 6 and 18 hours after stroke), whereas hemorrhagic transformation usually develops within 48 hours to 2 weeks. Intra cerebral hemorrhage (ICH) occurs as a result of bleeding from an arterial source directly into the brain parenchyma and accounts for $5-15 \%$ of all strokes (Campbell et al., 2019).

It is of particular importance to extract such patients who are prone to bleeding complications after anticoagulant or antiplatelet therapy. The detection of micro-bleeds on T2 weighted MRI might be a direct indicator for such a risk (Lane and Lip., 2010). Asymptomatic microbleeds shown by gradient echo T2weighted MRI are associated with small artery disease especially with intracerebral hemorrhage (Arsava et al., 2013).

The micro bleeds are frequently detected in patients with cerebral infarction as well as in patients with intracerebral hemorrhage and even in small number of healthy individuals without stroke episodes (Charidimou et al., 2012). Gradient- echo T2-weighted MRI is uniquely sensitive to detect silent, old hemosiderin, but the clinical significance of such "micro bleeds" remains to be determined. Micro bleeds were defined as small, silent foci of signal loss on T2 weighted MRI other than the principle lesion(s) responsible for stroke episode (Ovbiagele et al., 2013).

Recognizing bleeding prone microangiopathy in stroke patients is of extreme clinical significance when treating hypertensive patients with or without episodes of intracerebral hemorrhage (Shinohara et al., 2012).

There is a pathological confirmation that the micro bleeds on Gradient- echo T2-weighted MRI represent hemosiderin deposits. The deposits may be a result of minor blood leakage through damaged blood vessels in addition to frank minor hemorrhage. What-ever the source, they may remain detectable for years. The micro bleeds are barely detectable with T2-weighted spin echo MRI and are not visualized with other conventional scan (Haussen et al., 2012). 
The aim of this study was to determine the predictive factors of hemorrhagic transformation in patient with acute ischemic stroke detected by CT, MRI gradient echo T2 weighted image (GRE).

\section{PATIENTS AND METHODS}

This was a cross sectional randomized prospective study was carried out on 60 patients (32 males and 28 females), admitted at Neurology Department and Stroke Unit of Mostafa Kamel Military Hospital, with the first 24 hours of their symptoms. The study was carried out during the period from 1st. of January 2018 till the end of December 2018.

\section{Inclusion criteria:}

Patients within first time ischemic stroke, within the first 24 hours of their symptoms according WHO definition 2017 (WHO 2017).

\section{Exclusion criteria:}

1. Cerebral hemorrhage (subdural, extradural, intracerebral, subarachnoid hemorrhage) detect by initial CT brain.

2. Brain tumor and malignancy detect by initial CT brain.

3. Patients with contraindication for MRI, e.g. Pace maker.

\section{All patients were subjected to:}

\section{A. Clinical assessment:}

1. Stroke onset.

2. Full general and neurological history, and examination including demographic data: age, sex, occupation, family history of stroke, and history of stroke risk factors (as smoking, hypertension, diabetes mellitus, hyperchole-sterolemia, atrial fibrillation, and ischemic heart disease.

3. History of medications especially anticoagulants or anti platelets prior to the onset of stroke.

4. General and neurological examination.

\section{B. Radiological assessment:}

1. Computed tomography (CT) at admission for diagnosis and to exclude hemorrhage.

2. Magnetic resonance imaging (MRI) brain gradient echo T2 weighted image (GRE), within 24 hours from stroke onset.

3. Follow up computed tomography after seven days from onset or at any time of appearance of new symptoms, to detected hemorrhagic transformation.

MRI and CT recording were analyzed by radiologist to assess hemorrhagic transformation.

\section{Laboratory assessment:}

Laboratory investigations included complete blood picture, liver and renal function test, ESR, lipid profile, serum uric acid, PT, PTT and INR.

\section{Ethical considerations:}

Patients were consented by a written informed consent by patients or their close relatives before enrollment in this study.

This study was approved by ethical committee of Al-Azhar, Faculty of medicine (Cairo).

\section{Statistical analysis:}

The Data ware collected and entered into the personal computer. Statistical 


\section{HAMED G.H. IBRAHIM et al.,}

analysis was done using Statistical Package for Social Sciences (SPSS/version 21) software.
Arthematic mean, standard deviation, for categorized parameters, Chai square test was used, while for numerical data ttest was used to compare two groups. The level of significance was 0.05 .

\section{RESULTS}

This study was carried out on 60 patients (32 males and 28 females) recruited from Neurology Department of Mostafa Kamel Military Hospital, within the first 24 hours of their symptoms, during the period from beginning of January 2018 till the end of December 2018.

The age of our patients ranged from 45-72 years, with a mean age 57.5 \pm 8.32 years. Males represented $53.3 \%$ of the patients, while females represented $46.7 \%$. There were $25(42.2 \%)$ patients had a positive family history of stroke, 14 (23.3\%) patients had a past history of stroke. As regarding the comorbidity and risk factors, there were $25(41.7 \%)$ smoker patients, hypertension was found in 30 $(50.0 \%)$, patients, $20(33.3 \%)$ were diabetic, dyslipidemia was found in 30
(50.0\%), and cardiac disease in 15 $(25.0 \%)$ patients.

The size of infarction was small in size in $27(45.0 \%)$ patients, while the other 33 $(55.0 \%)$ patients had a large infarction size.

Lacunar infarction was defined as a small deep lesion (usually 5 to $15 \mathrm{~mm}$ in diameter) with high signal intensity on T2-weighted images, low signal intensity on T1-weighted, and FLAIR images with perilesional halo on FLAIR images, ruling out enlarged perivascular spaces and patchy leukoaraiosis (Gyanwali et al., 2019).

Of the 60 patients, $32(53.3 \%)$ had micro bleeds. Regarding hemorrhagic transformation of the patients, it was found that $11(18.3 \%)$ had a hemorrhagic transformation (Table 1).

Table (1): Microbleeds and hemorrhagic transformation of the studied patients group

\begin{tabular}{|l|c|c|}
\hline Counts & Number & Percent \\
\hline Parameters & 32 & \\
Yes & 28 & 53.3 \\
No & & \\
\hline Hemorrhagic transformation & 11 & 18.3 \\
Yes & 49 & 81.7 \\
No & \\
\hline
\end{tabular}

It was found that there was a significant relation between hemorrhagic transformation and size of infarction, the larger the size of infarction the higher percentage of hemorrhagic transformation $(\mathrm{p}<0.05)$. Also, there was a significant relation between hemorrhagic transformation and anticoagulant used.

There was a significant relation between hypertension and hemorrhagic 
transformation. The majority of hypertension patients had a hemorrhagic transformation $(p<0.05)$. There was a significant relation between hemorrhagic transformation and dyslipidemia. The patients with dyslipidemia had significantly a higher percentage of hemorrhagic transformation $(p<0.05)$. It was found that there was a significant association between cardiac patients and positive hemorrhagic transformation ( $p$ <0.05). Also, there was no significant relation between hemorrhagic transformation and DM, ( $>>0.05)$, (Table 2).

Table (2): Effect of different risk factors on hemorrhagic transformation

\begin{tabular}{|l|c|c|c|c|c|}
\hline \multirow{2}{*}{$\begin{array}{c}\text { Hemorrhagic } \\
\text { transformation }\end{array}$} & \multicolumn{2}{|c|}{$\begin{array}{c}\text { Negative } \\
\text { "n=49" }\end{array}$} & \multicolumn{2}{c|}{$\begin{array}{c}\text { Positive } \\
\text { "n=11” }\end{array}$} & $\begin{array}{c}\mathbf{X}^{2} \\
\text { p }\end{array}$ \\
\cline { 3 - 6 } Variables & No. & $\%$ & No. & $\%$ & \\
\hline Size of infarction & & & & & \\
$\quad$ Small & 26 & 53.1 & 1 & 9.1 & 7.017 \\
$\quad$ Large & 23 & 46.9 & 10 & 90.9 & $0.008^{*}$ \\
\hline Anticoagulant & & & & & \\
$\quad$ No & 48 & 98.0 & 6 & 54.5 & 18.81 \\
$\quad$ Yes & 1 & 2.0 & 5 & 45.5 & $0.0001^{*}$ \\
\hline Hypertension & & & & & \\
$\quad$ No & 28 & 57.1 & 2 & 18.2 & 5.45 \\
$\quad$ Yes & 21 & 42.9 & 9 & 81.8 & $0.019^{*}$ \\
\hline Diabetes mellitus & & & & & \\
$\quad$ No & 33 & 67.3 & 7 & 63.6 & 0.056 \\
$\quad$ Yes & 16 & 32.7 & 4 & 36.4 & 0.813 \\
\hline Dyslipidemia & & & & & \\
$\quad$ No & 27 & 55.1 & 3 & 27.3 & 2.78 \\
$\quad$ Yes & 22 & 44.9 & 8 & 72.7 & 0.095 \\
\hline Cardiac & & & & & \\
$\quad$ No & 44 & 89.8 & 1 & 9.1 & 32.45 \\
$\quad$ Yes & 5 & 10.2 & 10 & 90.9 & $0.0001^{*}$ \\
\hline
\end{tabular}

It was found that there was a significant relation between micro bleeds and hemorrhagic transformation. The majority of negative micro bleeds were negative hemorrhagic transformation ( $\mathrm{p}$ $<0.05)$. Also, it was found that there was a significant relation between micro bleeds and size of infarction. The smaller size of infarction the higher the presence of micro bleeds related with the positive micro bleeds ( $\mathrm{p}<0.05)$.

There was a significant relation between micro bleeds and dyslipidemia. The patients with dyslipidemia significantly had micro bleeds micro bleeds ( $p<0.05)$. There was a significant association between cardiac patients and positive micro bleeds ( $\mathrm{p}<0.05$ ). Also, there was a significant relation between past history of stroke and incidence of micro bleeds, hypertension and micro bleeds, the majority of positive micro bleeds had a hypertension ( $\mathrm{p}<0.05$ ).

No significant relation between anticoagulant and micro bleeds, between smoking and micro bleeds, and between micro bleeds and DM (Table 3 ). 
HAMED G.H. IBRAHIM et al.,

Table (3): The association between different risk factors and micro bleeds

\begin{tabular}{|c|c|c|c|c|c|}
\hline \multirow[t]{2}{*}{ Microbleeds } & \multicolumn{2}{|c|}{$\begin{array}{l}\text { Positive } \\
\text { "n=32" }\end{array}$} & \multicolumn{2}{|c|}{$\begin{array}{l}\text { Negative } \\
" n=28 "\end{array}$} & \multirow{2}{*}{$\begin{array}{c}X^{2} \\
p\end{array}$} \\
\hline & No. & $\%$ & No. & $\%$ & \\
\hline $\begin{array}{l}\text { Hemorrhagic transformation } \\
\text { Negative } \\
\text { Positive }\end{array}$ & $\begin{array}{l}21 \\
11\end{array}$ & $\begin{array}{l}65.6 \\
34.4\end{array}$ & $\begin{array}{c}28 \\
0\end{array}$ & $\begin{array}{l}100 \\
0.0\end{array}$ & $\begin{array}{c}9.20 \\
0.0024 *\end{array}$ \\
\hline $\begin{array}{l}\text { Size of infarction } \\
\text { Small } \\
\text { Large } \\
\end{array}$ & $\begin{array}{l}20 \\
12 \\
\end{array}$ & $\begin{array}{l}62.5 \\
37.5 \\
\end{array}$ & $\begin{array}{c}7 \\
21 \\
\end{array}$ & $\begin{array}{l}25.0 \\
75.0\end{array}$ & $\begin{array}{c}8.48 \\
0.004 *\end{array}$ \\
\hline $\begin{array}{l}\text { Anticoagulant } \\
\text { No } \\
\text { Yes } \\
\end{array}$ & $\begin{array}{c}27 \\
5 \\
\end{array}$ & $\begin{array}{l}84.4 \\
15.6\end{array}$ & $\begin{array}{c}27 \\
1 \\
\end{array}$ & $\begin{array}{c}96.4 \\
3.6 \\
\end{array}$ & $\begin{array}{c}2.41 \\
0.120\end{array}$ \\
\hline $\begin{array}{l}\text { Smoking } \\
\text { No } \\
\text { Yes }\end{array}$ & $\begin{array}{l}17 \\
15\end{array}$ & $\begin{array}{l}53.1 \\
46.9\end{array}$ & $\begin{array}{l}18 \\
10\end{array}$ & $\begin{array}{l}64.3 \\
35.7\end{array}$ & $\begin{array}{l}0.768 \\
0.381\end{array}$ \\
\hline $\begin{array}{l}\text { Past history of stroke } \\
\text { No } \\
\text { Yes } \\
\end{array}$ & $\begin{array}{l}18 \\
14 \\
\end{array}$ & $\begin{array}{l}56.3 \\
43.7 \\
\end{array}$ & $\begin{array}{c}28 \\
0 \\
\end{array}$ & $\begin{array}{c}100.0 \\
0.0 \\
\end{array}$ & $\begin{array}{c}13.32 \\
0.0002 *\end{array}$ \\
\hline $\begin{array}{l}\text { Hypertension } \\
\text { No } \\
\text { Yes }\end{array}$ & $\begin{array}{c}6 \\
26\end{array}$ & $\begin{array}{l}18.8 \\
81.2\end{array}$ & $\begin{array}{c}24 \\
4\end{array}$ & $\begin{array}{l}85.7 \\
14.3\end{array}$ & $\begin{array}{c}26.79 \\
0.0001 *\end{array}$ \\
\hline $\begin{array}{l}\text { Diabetes mellitus } \\
\text { No } \\
\text { Yes }\end{array}$ & $\begin{array}{l}20 \\
12 \\
\end{array}$ & $\begin{array}{l}62.5 \\
37.5 \\
\end{array}$ & $\begin{array}{c}20 \\
8 \\
\end{array}$ & $\begin{array}{l}71.4 \\
28.6 \\
\end{array}$ & $\begin{array}{l}0.535 \\
0.464 \\
\end{array}$ \\
\hline $\begin{array}{l}\text { Dyslipidemia } \\
\text { No } \\
\text { Yes }\end{array}$ & $\begin{array}{c}7 \\
25\end{array}$ & $\begin{array}{l}21.9 \\
78.1\end{array}$ & $\begin{array}{c}23 \\
5\end{array}$ & $\begin{array}{l}82.1 \\
17.9\end{array}$ & $\begin{array}{c}21.69 \\
0.001 *\end{array}$ \\
\hline $\begin{array}{l}\text { Cardiac } \\
\text { No } \\
\text { Yes }\end{array}$ & $\begin{array}{l}19 \\
13\end{array}$ & $\begin{array}{l}59.4 \\
40.6\end{array}$ & $\begin{array}{c}26 \\
2\end{array}$ & $\begin{array}{c}92.9 \\
7.1\end{array}$ & $\begin{array}{c}8.93 \\
0.0028^{*}\end{array}$ \\
\hline
\end{tabular}

\section{DISCUSSION}

The results of our study showed that the size of infarction was small in $45.0 \%$ patients, and large in $55.0 \%$ of patients. The radiological assessment of the studied patients group was found in $53.3 \%$ patients had micro bleeds.

In agreement with our results, Lee et al (2018) found that the size of infarction ranged from 2-10 $\mathrm{ml}$. The small and large infarction was divided in the studied cases without significant difference.

Also, in our study, the hemorrhagic transformation of the patients was found that $18.3 \%$ patients had a hemorrhagic transformation. In agreement with our study, Li et al (2017) found that the incidence of hemorrhagic transformation among cerebral micro bleeds was $13.8 \%$

In our study, the results showed that there was a significant relation between micro bleeds and hemorrhagic transformation. The majority of negative micro bleeds was negative hemorrhagic transformation. Also, there was a positive relation between micro bleeds and size of infarction, the small size related with the positive micro bleeds. No significant 
relation between past history of sroke and micro bleeds.

These results were in agreement with Lovelock et al (2010) and Charidimou et al (2012 who found that micro bleeds have been associated with stroke history in patients taking anticoagulant medications in cross-sectional casecontrol, case-case comparisons and small case series studies, suggesting that there may be a stronger predictor of anticoagulant-associated ICH than leukoaraiosis.

In this study, there was a significant relation between hypertension and micro bleeds. The majority of hypertensive patients had micro bleeds.

Lioutas et al. (2017) showed that hypertension was frequent in intracerebral hemorrhage and lacunar infarction. Therefore, the presence of multiple micro bleeds suggests that the microangiopathy has reached an advanced stage, in which the blood vessels are prone to bleeding. Another explanation may be cerebral amyloid angiopathy, which is also a small artery disease in the non-hypertensive elderly, presenting lobar hemorrhage with the coexistence of lacunar infarcts and white matter lesions.

There was a significant relation between micro bleeds and DM. From 20 diabetic patients, 14 patients were positive micro bleeds.

Several studies have reported that CMBs are significantly associated with DM, atherosclerosis, lacunar infarct, and stroke. In addition, it may contribute to cognitive impairment. Therefore, CMBs serve as an independent risk factor for the progression of MCI to dementia (Hong et al., 2017). The clinical symptoms of cerebral hemorrhage are primarily dependent on the location and number of CMBs. The progression of vascular cognitive impairment may be accelerated with an increase in the number of CMBs (Nardone et al., 2011). With the emergence of cerebral hemorrhage, the severity of cognitive impairment also increases, which suggests an accumulation effect (Ihn et al., 2013).

In our study, it was found that there was a significant relation between micro bleeds and dyslipidemia, the patients with dyslipidemia was significantly had positive micro bleeds.

Cholesterol, diabetes mellitus, and smoking have also been reported as risk factors for micro bleeds, but the results differ according to the study. Some studies have shown hypercholesterolemia lowers the risk of micro bleeds, and statin therapy increases the risk of cerebral hemorrhage (Ducrocq et al., 2013) in meta-analysis results showed the opposite. Cystatin C, a renal function indicator, has been associated with deep and infratentorial $\mathrm{CMB}$, as well as chronic kidney disease, implicating it as a risk factor for CMB (Hackam et al., 2011 and Oh et al., 2014).

Yates et al. (2014) found that the development of new micro bleeds associated with the progression of ischemic vascular brain lesions. Concurrent progressions of hemorrhagic and ischemic vascular brain lesions support the hypothesis of a common pathophysiologic pathway for these lesions.

It was found that there was a significant association between cardiac 


\section{HAMED G.H. IBRAHIM et al.,}

patients and positive micro bleeds ( $p$ $<0.05)$.

Evidence that micro bleeds also associate with ischemic or occlusive brain disease was found in meta-analysis of clinical studies (Charidimou et al., 2013).

Naganuma et al. (2015) found that CMBs statistically significant predictors of ICH, and they have confirmed previous observations of a predominance of lobar CMBs in patients with ICH. Haussen et al. (2012) suggested that the presence of micro bleeds reflects a more diffuse pathologic process in the brain by showing that white matter changes surround the actual micro bleeds.

In this study, there was a significant relation between use of anticoagulant and hemorrhagic transformation. This was in agreement to Lovelock et al. (2010). Antithrombotic drug use and anticoagulant drugs increase risk of micro bleed and hemorrhagic transformation Lovelock et al. (2010). They showed that the use of oral anticoagulant drug associates with an increased risk of developing new micro bleeds. More importantly, they found proof that a higher maximum INR, and fluctuations of INR during the initiation period of anticoagulant use were both associated with higher prevalence of micro bleeds. Charidimou et al. (2011) showed that CMBs are markers of more advanced cerebrovascular disease and severe underlying microangiopathy, and presence of leukoaraiosis is a risk factor for warfarin-related $\mathrm{ICH}, \mathrm{CMBs}$ might contribute to increase the risk of warfarinrelated ICH. Ge et al. (2011) found that, in patients with ischemic cerebrovascular disease only (i.e. IS or TIA), CMBs were more frequent in aspirin users compared with non-users especially after long exposure to aspirin (greater than 5 years) although a confounding effect of cerebrovascular disease could not be completely eliminated.

\section{CONCLUSION}

The risk factor of hemorrhagic transformation was large size of infection, hypertension, anticoagulant use and cardiac disease, while the most predictive factors of micro bleeds were the age of the patient, size of infarction, past history of stroke, hypertension, dyslipidemia, diabetes mellitus, anticoagulant use and cardiac disease.

\section{REFERENCES}

1. Arsava E., Kayim-Yildiz O., Oguz K., Akpinar E. and Topcuoglu M. (2013): Elevated Admission Blood Pressure and Acute Ischemic Lesions in Spontaneous Intracerebral Hemorrhage. Journal of Stroke and Cerebrovascular Diseases, 22(3): 250254.

2. Campbell B., Silva D., Macleod M., Coutts S., Schwamm L., Davis S. and Donnan G. (2019): Ischaemic stroke. Nature Reviews Disease Primers. 5(1): 1-22.

3. Charidimou A., Gang Q. and Werring DJ. (2012): Sporadic cerebral amyloid angiopathy revisited: recent insights into pathophysiology and clinical spectrum. J Neurol Neurosurg Psychiatry, 83: 124-37.

4. Charidimou A., Kakar P., Fox Z. and Werring D. (2013): Cerebral micro bleeds and recurrent stroke risk: systematic review and meta-analysis of prospective ischemic stroke and transient ischemic attack cohorts. Stroke, 44: 995-1001.

5. Charidimou A., Shakeshaft C. and Werring DJ. (2012): Cerebral micro bleeds on magnetic resonance imaging and anticoagulant-associated intracerebral hemorrhage risk. Frontiers in Neurology, 3: $1-13$. 
6. Charidimou A. and Werring D. (2011): Cerebral micro bleeds: detection, mechanisms and clinical challenges. Future Neurology. 6(5): 587-611.

7. Ducrocq G., Amarenco P., Labreuche J. Alberts M., Mas J., Ohman E., Goto S. Lavallèe P., Bhatt D. and Steg P. (2013): A History of Stroke/Transient Ischemic Attack Indicates High Risks of Cardiovascular Event and Hemorrhagic Stroke in Patients With Coronary Artery Disease. Circulation. 127: 730-738.

8. Ge L., Niu G., Han X., Gao Y., Wu Q., Wu H., Zhang Y. and Guo D. (2011): Aspirin treatment increases the risk of cerebral micro bleeds. Can J Neurol Sci, 38: 863-8.

9. Gyanwali B., Vrooman H., Venketasubramanian N., Wong TY., Cheng CY., Chen C. and Hilal S. (2019): Cerebral Small Vessel Disease and Enlarged Perivascular Spaces-Data From Memory Clinic and Population-Based Settings. Front. Neurol., 10:669.

10. Hackam DG., Woodward M., Newby LK., Bhatt DL., Shao M., Smith EE. and Donner A. (2014): Statins and intracerebral hemorrhage: collaborative systematic review and meta-analysis. Circulation, 124:22332242.

11. Haussen D., Henninger N., Kumar S. and Selim M. (2012): Statin Use and Micro bleeds in Patients with Spontaneous Intracerebral Hemorrhage. 43: 2677-2681.

12. Hong Z., Juan Y., Peihan X., Dong Y., You Y. and Liu J. (2017): Cerebral micro bleeds, cognitive impairment, and MRI in patients with diabetes mellitus. Clinica Chimica Acta. 470: 14-19.

13. Ihn Y., Jung W. and Hwang S. (2013): Clinical Imaging. The value of T $2 *$-weighted gradient-echo MRI for the diagnosis of cerebral venous sinus thrombosis. Clin Imaging. 37(3): 446-450.

14. Lane D. and Lip G. (2010): Dabigatran in atrial fibrillation: balancing secondary stroke prevention against bleeding risk. Reflection and Reaction, 9 (12): P1140-1142.
15. Lee J., Sohn EH., Oh E. and Lee AY. (2018): Characteristics of Cerebral Micro bleeds. Dement Neurocogn Disord., 17(3): 73-82.

16. Li L., Liu MS., Li GQ., Zheng Y., Guo TL., Kang X. and Yuan, MT. (2017): Susceptibility-weighted Imaging in Thrombolytic Therapy of Acute Ischemic Stroke. Chinese medical journal, 130(20): 2489-2497.

17. Lioutas VA., Beiser A., Himali J., Aparicio H., Romero JR., DeCarli C. and Seshadri S. (2017): Lacunar Infarcts and Intracerebral Hemorrhage Differences: A Nested CaseControl Analysis in the FHS (Framingham Heart Study). Stroke, 48(2): 486-489.

18. Lovelock CE., Cordonnier C., Naka H., Salman R. and Sudlow C. (2010): Antithrombotic drug use, cerebral micro bleeds, and intracerebral hemorrhage: a systematic review of published and unpublished studies. Stroke, 41: 1222-8.

19. Malhotra K. and Liebeskind DS. (2017): Overview of Neuroimaging of Stroke. Primer on Cerebrovascular Diseases (Second Edition), Chapter 130: 676-685.

20. Naganuma T, Takemoto $Y$, Shoji T, Ishimura E, Okamura M. and Nakatani T. (2015): Cerebral Micro bleeds Predict Intracerebral Hemorrhage in Hemodialysis Patients. Stroke, 46:2107-2112.

21. Nardone R., Blasi P., Seidl M., Höller Y., Caleri F., Tezzon F., Ladurner G., Golaszewski S. and Trinka E. (2011): Cognitive function and cholinergic transmission in patients with subcortical vascular dementia and micro bleeds: a TMS study. Journal of Neural Transmission. 118: 13-49.

22. Oh MY., Lee H., Kim JS., Ryu WS., Lee SH., Ko SB., Kim CH. and Yoon BW. (2014): Cystatin $C$, a novel indicator of renal function, reflects severity of cerebral micro bleeds. BMC Neurol., 14:127.

23. Ovbiagele B., Wing J., Menon R., Burgess R., Gibbons MC., Sobotka I., German L., Shara NM. and Fernandez S. (2013): Association of Chronic Kidney Disease With 


\section{HAMED G.H. IBRAHIM et al.,}

Cerebral Micro bleeds in Patients With Primary Intracerebral Hemorrhage. Stroke., 44:2409-2413.

24. Sacco LR., Kasner S., Bropadeick J., Caplan L., Culebras A., Mitchell S., George Michael $M$. and Vinters HV. (2013): An Updated Definition of Stroke for the 21st Century. Stroke, 44(7): 2064-2089.

25. Saji N., Kimura K., Tateishi Y., Fujimoto S., Kaneko N., Urabe T., Tsujino A. and Iguchi Y. (2016): Safety and efficacy of nonvitamin $\mathrm{K}$ oral anticoagulant treatment compared with warfarin in patients with nonvalvular atrial fibrillation who develop acute ischemic stroke or transient ischemic attack: a multicenter prospective cohort study (daVinci study). Journal of Thrombosis and Thrombolysis 42: 453-462.

26. Shinohara Y., Kinoshita T. and Kinoshita F. (2012): Changes in susceptibility signs on serial T2*-weighted single-shot echo-planar gradient-echo images in acute embolic infarction: comparison with recanalization status on 3D time-of-flight magnetic resonance angiography. Neuro-radiology. 54: 427-434.

27. World Health Organization (2017): WHO Methods and Data Sources for Country-level Causes of Death 2000-2015. Department of Information, Evidence and Research WHO, Geneva. Available at: http://www. who.int/gho/ mortality_ burden_ disease/ en/index.html.

28. Yates PA., Villemagne VL., Ellis KA., Desmond PM., Masters CL. and Rowe CC. (2014): Cerebral micro bleeds: a review of clinical, genetic, and neuroimaging associations. Front Neurol., 4:205- 208. 


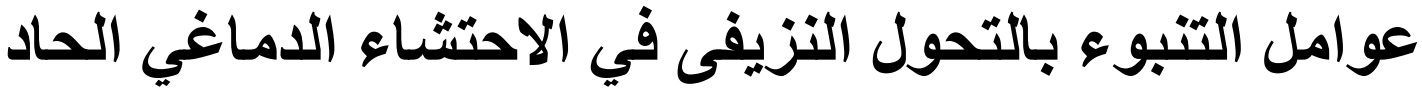

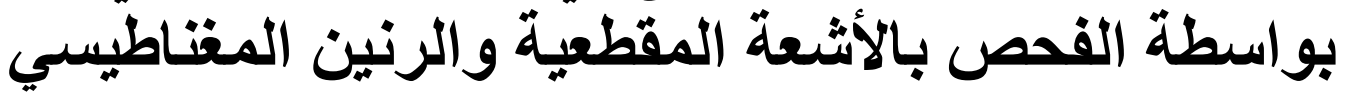

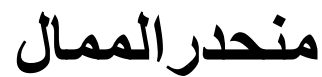

حامد جمعه إبراهيم، طارق إبراهيم منيسى1، خالد إبراهيم النويعم²، محمد أحمد3،

$$
\text { أحمد فرج إبراهيم1 }
$$

1قسم الأعصاب كلية الطب، جامعة الأزهر

2قسم الأشعة التشخيصية بكلية الطب جامعة الإسكندرية

3قسم الباثولوجيا الإكلينيكية، أكاديمية القوات المسلحة الطبية

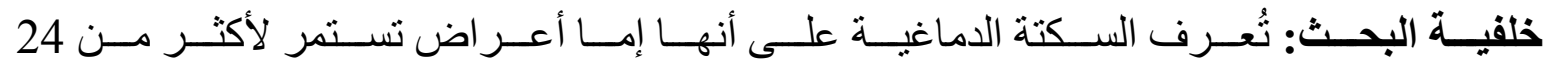

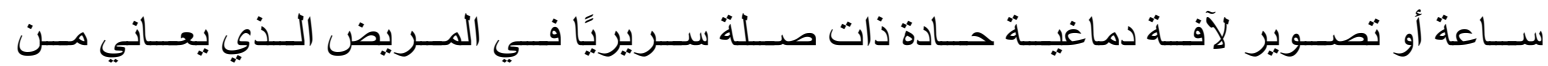

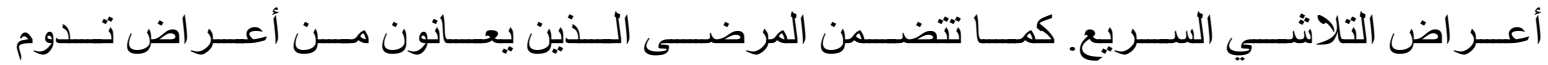

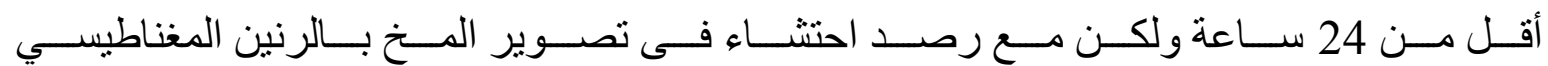

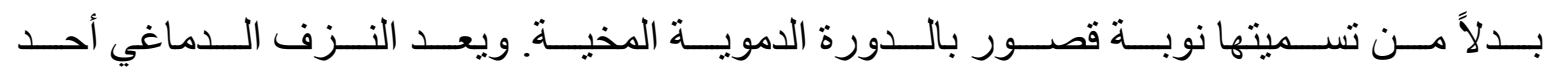

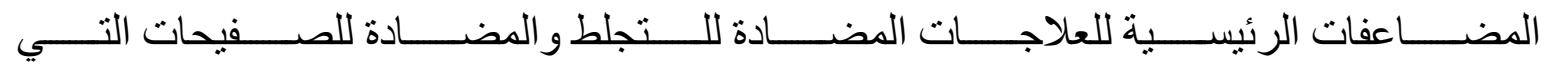

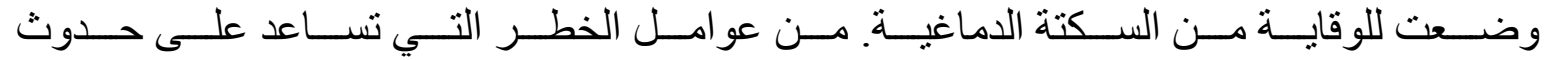

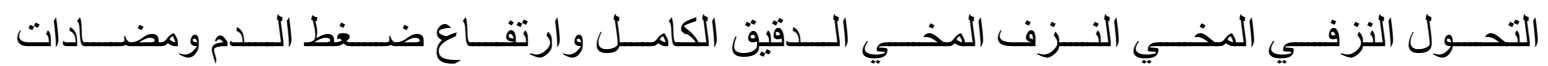

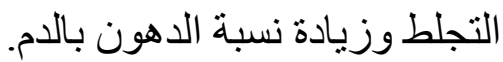

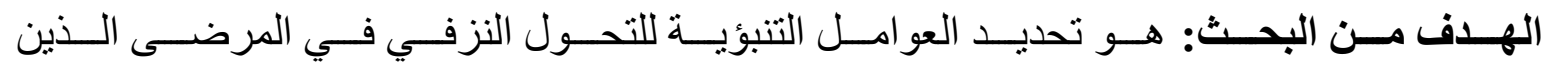

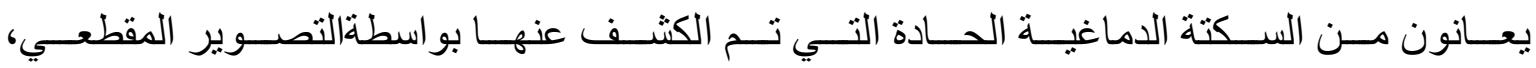
التصوير بالرنين المغناطيسي منحدر الممال.

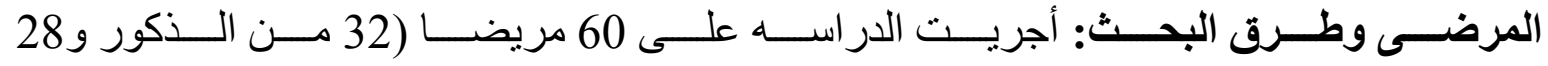

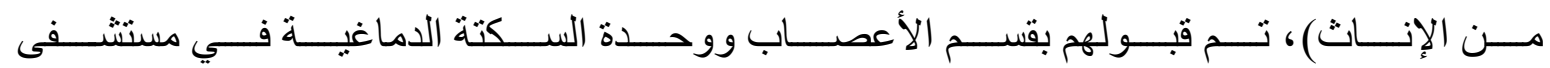

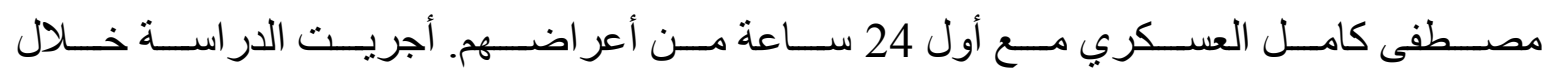
الفترة من بداية يناير 2018 حتى نهاية ديسمبر 2018. 


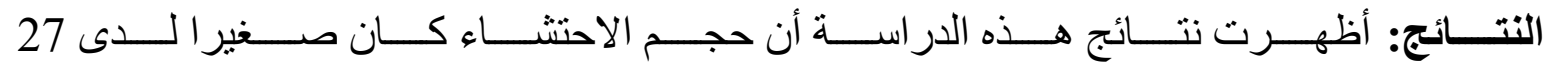

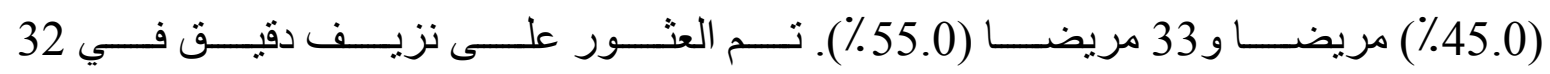

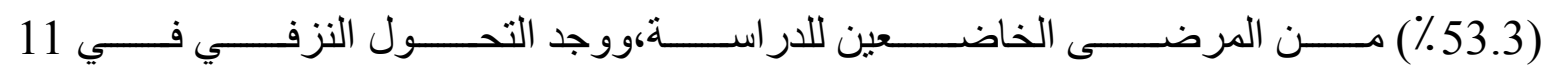

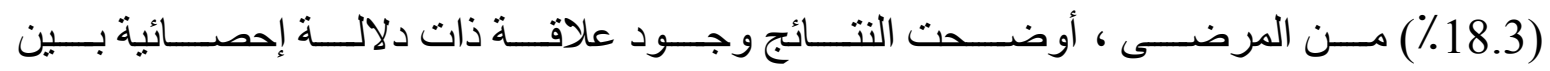

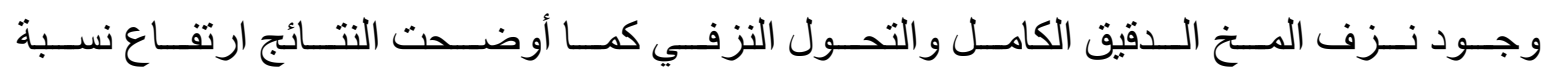

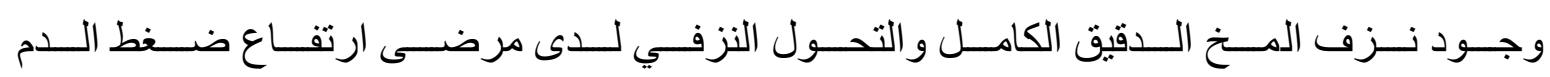

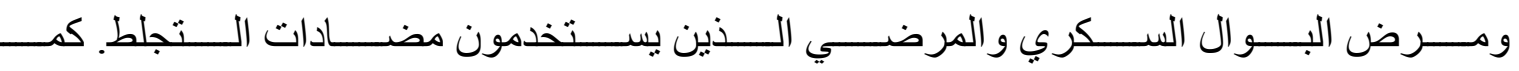

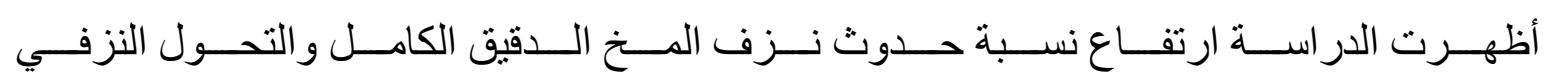
للمرضى الذين كان لهم تاريخ سابق لحدوث جلطات المخ.

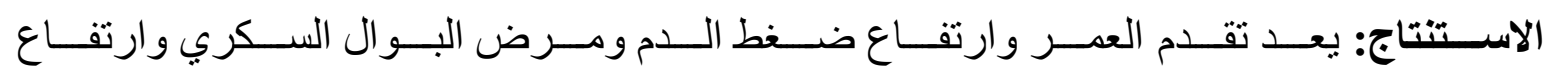

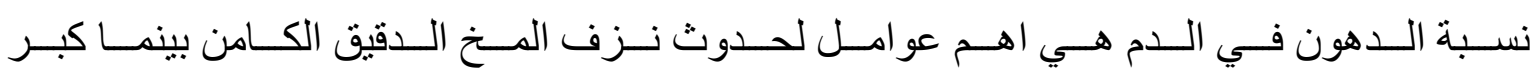

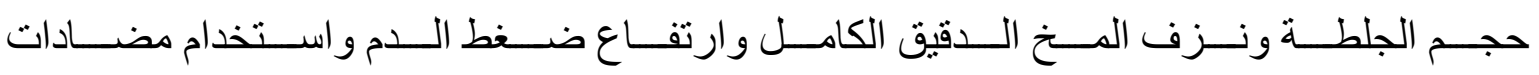
التجلط هي اهم العوامل المسبية للتحول النزفي المخي. 